\title{
Identifikasi pola ruang dan perubahan fungsi ruang Puri Pemecutan Denpasar
}

\author{
A.A.Ngurah Ari Putra Pratama ${ }^{1}$, Lury Sevita Yusiana ${ }^{1 *}$, A.A. Made Astiningsih ${ }^{2}$ \\ 1. Prodi Arsitektur Pertamanan, Fakultas Pertanian, Universitas Udayana, Indonesia \\ 2. Prodi Agroekoteknologi, Fakultas Pertanian, Universitas Udayana, Indonesia
}

*E-mail: lury.yusiana@unud.ac.id

\begin{abstract}
Identification on spatial patterns and changes of Pemecutan Castle Denpasar. Puri Pemecutan is one of royal palaces (puri) in Denpasar city which has a very high historical value. The puri has a different spatial pattern compared to traditional Balinese house in general. The magnitude of royal palaces family needs of residence and the number of activities carried out by the puri's family caused a change of pattern and function of each space in Puri Pemecutan. The aims of this study is to identify spatial patterns and functions of the Puri Pemecutan in 1942 and 2016, and identify changes in spatial patterns and functions that occur in Puri Pemecutan. The research method used was survey with data collection is observation, interview, and study leterature by descriptive qualitative method. The step of this research starts from the inventory, analysis, synthesis, and recommendation. The result of this research showed that the pattern of space and space function were change of the Puri Pemecutan in 1942 and year 2016. The study also give recommendations of spatial puri based on changes of space function change of the Puri Pemecutan.
\end{abstract}

Keywords: puri pemecutan, spatial patterns, space function changes

\section{Pendahuluan}

Bali merupakan salah satu daerah di Indonesia yang memilki sistem stratifikasi sosial pada masyarakatnya. Sistem stratifikasi sosial merupakan pembedaan posisi seseorang atau kelompok dalam kedudukan berbeda-beda secara vertical (Soekanto, 1990). Kasta di Bali dibagi menjadi empat kasta yaitu kasta Brahmana, Kesatria, Waisya, dan Sudra (Wiana, 2006). Sistem kasta di Bali dapat dibedakan dari beberapa wujud rumah tinggal, Perbedaan tersebut dapat dilihat pada luas pekarangan, susunan ruang, tipe bangunan, fungsi, bentuk dan material yang digunakan yang diatur dalam Asta Kosala Kosali (Gelebet, 1986). Sistem kasta dapat dibedakan dari beberapa wujud rumah tinggal, salah satunya yaitu puri. Puri memiliki pola ruang yang berbeda dengan pola ruang pada rumah tradisional Bali pada umumnya. Puri merupakan pusat pemerintahan pada jaman dahulu dan juga sebagai tempat tinggal yang berdasarkan atas tingkatan kasta yang tergolong dalam tingkatan utama atau tempat tinggal untuk golongan raja atau kesatria. Puri biasanya terletak pada Perempatan Agung dan fasilitas-fasilitas umum yang ada di kompleks Perempatan Agung seperti pasar, Bancingah (Wantilan), dan ruang terbuka merupakan beberapa hal yang menentukan status dan tingkat kekuasaan puri (Putra, 1998).

Puri Pemecutan merupakan salah satu puri di Kota Denpasar yang memiliki nilai historis yang sangat tinggi. Puri Pemecutan berperan juga dalam peperangan saat melawan penjajah Belanda di Bali. Besarnya nilai historis yang dimiliki Puri Pemecutan, menyebabkan Puri Pemecutan saat ini dijadikan sebagai salah satu tempat wisata sejarah yang ada di Bali.

Berkembangnya Bali menjadi daerah pariwisata berimbas pada perubahan fungsi dan tata bangunan terhadap puri, karena Puri Pemecutan pernah dijadikan sebagai hotel oleh keluarga puri sehingga pola ruang dan fungsi ruang di Puri Pemecutan mengalami perubahan. Perubahan ini terlihat pada berubahnya fungsifungsi dari bangunan yang terdapat pada puri, selain itu bertambahnya jumlah penghuni puri menyebabkan penghuni puri berusaha untuk memenuhi kebutuhannya akan tempat tinggal. Besarnya kebutuhan keluarga puri akan tempat tinggal dan banyaknya aktivitas yang dilakukan oleh keluarga puri, menimbulkan perubahan pola, fungsi, serta dampak dari peubahan pola dan fungsi pada masing-masing ruang yang ada di Puri Pemecutan.

Tujuan dari penelitian ini yaitu Mengidentifikasi pola dan fungsi ruang di Puri Pemecutan pada tahun 1942 dan pola ruang Puri Pemecutan pada tahun 2016, Mengidentifikasi perubahan pola dan fungsi ruang yang terjadi di Puri Pemecutan, Mengidentifikasi dampak yang terjadi dari perubahan pola ruang di Puri Pemecutan. 


\section{Metode Penelitian}

\subsection{Waktu dan Tempat Penelitian}

Penelitian ini dilaksanakan di Puri Pemecutan, Desa Pemecutan Kaja, Kota Denpasar, Bali dan beralamat di jalan Thamrin No. 2 Denpasar. Penelitian ini dilakukan selama delapan bulan yaitu pada bulan November 2016 sampai dengan Juli 2017.

\subsection{Alat dan Bahan}

Alat yang digunakan dalam penelitian ini yaitu, alat tulis, lembar daftar pertanyaan, laptop, kamera digital, dan alat ukur meteran. Bahan yang digunakan dalam penelitian ini yaitu denah Puri Pemecutan pada tahun 1942 dan denah Puri Pemecutan pada tahun 2016.

\subsection{Metode Penelitian}

Penelitian ini menggunakan metode survei dengan teknik observasi, wawancara, dan studi pustaka dengan penyajian deskriptif kualitatif. Tahapan pada penelitian ini dimulai dari tahap inventarisasi, analisis, sintesis, dan tahap rekomendasi.

\subsubsection{Inventarisasi}

Tahap pengumpulan data merupakan tahap yang dilakukan untuk mengumpulkan data mengenai pola ruang Puri Pemecutan. Data yang dikumpulkan pada tahapan ini yaitu data fisik dan sosial, serta mengindentifikasi pola ruang Puri Pemecutan pada tahun 1942 dan pola ruang Puri Pemecutan saat 2016.

\subsubsection{Analisis}

Tahap analisis dilakukan untuk mengidentifikasi perubahan fungsi ruang dan dampak yang ditimbulkan dari perubahan fungsi ruang di Puri Pemecutan. Tahap ini juga menganalisis penyebab perubahan pola ruang dan mengetahui dampak yang ditimbulkan dari perubahan pola ruang yang terjadi di Puri Pemecutan Denpasar.

\subsubsection{Sintesis}

Tahap sintesis merupakan tahapan pemecahan masalah obyek penelitian berdasarkan hasil dari analisis yang telah dilakukan. Tahap sintesis bertujuan untuk memberikan solusi pada pola ruang yang sesuai bagi Puri Pemecutan berdasarkan dari fungsi ruang yang dibutuhkan.

\subsubsection{Rekomendasi}

Tahap rekomendasi bertujuan untuk memberikan rekomendasi tentang rencana tata ruang berdasarkan hasil dari tahapan analisis, sintesis, dan bedasarkan fungsi dari masing-masing ruang yang terdapat di Puri Pemecutan.

\subsection{Batasan Studi}

Penelitian ini dilakukan di Puri Pemecutan Denpasar dengan tujuan untuk mengidentifikasi pola ruang, perubahan fungsi ruang, dan dampak dari perubahan fungsi

ruang di Puri Pemecutan Denpasar. Penelitian ini diharapkan menghasilkan rekomendasi tata ruang Puri Pemecutan.

\section{Hasil dan Pembahasan}

\subsection{Gambaran Umum Puri Pemecutan}

Puri Pemecutan terletak di Desa Pemecutan, Kecamatan Denpasar Barat, Kota Denpasar, Bali. Puri Pemecutan terletak di arah Kaja - Kangin (Timur Laut) dari catus patha Puri Pemecutan yang merupakan persimpangan dari jalan Hasanuddin, jalan Imam Bonjol, jalan Gunung Batur, dan Jalan Thamrin. Batas-batas Puri Pemecutan adalah pada bagian barat yakni jalan Thamrin, bagian utara dibatasi oleh Puri Ukir Pemecutan, bagian timur puri dibatasi oleh perumahan, dan bagian selatan puri dibatasi jalan Hasanuddin. Puri Pemecutan memiliki luas sekitar $8.000 \mathrm{~m}^{2}$. Luas Puri Pemecutan pada saat ini masih sama dengan luas puri pada tahun 1942.

\subsection{Identifikasi Pola Ruang Puri Pemecutan}

Pola ruang yang ada di Puri Pemecutan dibagi menjadi beberapa ruang yaitu ruang utama Merajan, Jaba Tengah Merajan, Jaba Sisi Merajan, Natah atau ruang pribadi, Jaba Tengah puri atau ruang publik, dan Jaba Sisi puri, masing-masing ruang dihubungkan dengan pintu masuk yang disebut kori (Pemecutan wawancara 17 April 2016). Perbedaan pola ruang puri tahun 1942 dengan pola ruang tahun 2016 yaitu terlihat pada jumlah bangunan dan perubahan fungsi bangunan.

Pola ruang Puri Pemecutan pada tahun 1942 dan tahun 2016 dapat dibagi berdasarkan konsep $T r i$ Mandala, dimana konsep Tri Mandala terdiri dari Utama Mandala, Madya Mandala, dan Nista Mandala. Berdasarkan konsep Tri Mandala, pola ruang Puri Pemecutan tahun 1942 dan pola ruang puri tahun 2016 dapat dilihat pada tabel berikut (Tabel 1). 
Tabel 1. Pola Ruang Puri Pemecutan Berdasarkan Konsep Tri Mandala Tahun 1942

\begin{tabular}{|c|c|c|c|c|c|c|c|c|}
\hline \multirow{3}{*}{$\begin{array}{l}\text { Zona } \\
\text { Ruang }\end{array}$} & \multirow{3}{*}{$\begin{array}{l}\text { Bagian } \\
\text { Zona Ruang }\end{array}$} & \multirow{3}{*}{ Bangunan } & \multirow{3}{*}{$\begin{array}{c}\text { Luas } \\
\text { Bangunan } \\
\left.\qquad \mathrm{m}^{2}\right)\end{array}$} & \multicolumn{4}{|c|}{ Luas Bagian Zona Ruang } & \multirow{3}{*}{$\begin{array}{l}\text { Total Luas } \\
\text { Ruang }\left(\mathrm{m}^{2}\right)\end{array}$} \\
\hline & & & & \multicolumn{2}{|c|}{ Bangunan } & \multicolumn{2}{|c|}{ Ruang Terbuka } & \\
\hline & & & & $\mathrm{m}^{2}$ & $\%$ & $\mathrm{~m}^{2}$ & $\%$ & \\
\hline Utama & Utama & - Pelinggih & 234,62 & 314,6 & $35 \%$ & 595,3 & $65 \%$ & 909,9 \\
\hline Mandala & Merajan & $\begin{array}{l}\text { - Bale Gong } \\
\text { - Bale Pemiosan }\end{array}$ & $\begin{array}{l}23,4 \\
56,58\end{array}$ & & & & & \\
\hline \multirow[t]{10}{*}{$\begin{array}{l}\text { Madya } \\
\text { Mandal }\end{array}$} & $\begin{array}{l}\text { - Jaba } \\
\text { Tengah } \\
\text { Merajan }\end{array}$ & $\begin{array}{l}\text { - Tidak terdapat } \\
\text { bangunan }\end{array}$ & & & & 468,7 & $100 \%$ & 468,7 \\
\hline & - Natah & - Saren Dangin & 42,9 & 268,5 & $5 \%$ & 4656,4 & $95 \%$ & 4924,9 \\
\hline & & - Saren Daja & 51,2 & & & & & \\
\hline & & - Saren Delod & 46,2 & & & & & \\
\hline & & - Saren Dauh & 46,2 & & & & & \\
\hline & & - Pewaregan & 40 & & & & & \\
\hline & & - Jineng (3 unit) & 12 & & & & & \\
\hline & & $\begin{array}{l}\text { - Pemandian } \\
\quad \text { Raja }\end{array}$ & 30 & & & & & \\
\hline & - Jaba & - Bale Room & 288,8 & 430,2 & $35 \%$ & 813,7 & $65 \%$ & 1243,9 \\
\hline & $\begin{array}{l}\text { Tengah } \\
\text { Puri }\end{array}$ & - Bale Panjang & 141,4 & & & & & \\
\hline \multirow{3}{*}{$\begin{array}{l}\text { Nista } \\
\text { Mandala }\end{array}$} & - Jaba Sisi & - Tidak terdapat & & & & 266,8 & $100 \%$ & 266,8 \\
\hline & Merajan & bangunan & & & & & & \\
\hline & $\begin{array}{l}\text { - Jaba Sisi } \\
\text { Puri }\end{array}$ & - Bale Kulkul puri & 67,4 & 67,4 & $5 \%$ & 1297 & $95 \%$ & 1364,4 \\
\hline
\end{tabular}

Tabel 2. Pola Ruang Puri Pemecutan berdasarkan Konsep Tri Mandala Tahun 2016

\begin{tabular}{|c|c|c|c|c|c|c|c|c|}
\hline \multirow{3}{*}{$\begin{array}{l}\text { Zona } \\
\text { Ruang }\end{array}$} & \multirow{3}{*}{$\begin{array}{l}\text { Bagian } \\
\text { Zona } \\
\text { Ruang }\end{array}$} & \multirow{3}{*}{ Bangunan } & \multirow{3}{*}{$\begin{array}{l}\text { Luas } \\
\text { Bangunan } \\
\qquad\left(\mathrm{m}^{2}\right)\end{array}$} & \multicolumn{4}{|c|}{ Luas Bagian Zona Ruang } & \multirow{3}{*}{$\begin{array}{l}\text { Total Luas } \\
\text { Ruang }\left(\mathrm{m}^{2}\right)\end{array}$} \\
\hline & & & & \multicolumn{2}{|c|}{ Bangunan } & \multicolumn{2}{|c|}{ Ruang Terbuka } & \\
\hline & & & & $\mathrm{m}^{2}$ & $\%$ & $m^{2}$ & $\%$ & \\
\hline $\begin{array}{l}\text { Utama } \\
\text { Mandala }\end{array}$ & $\begin{array}{ll}\text { - } & \text { Utama } \\
& \text { Merajan }\end{array}$ & $\begin{array}{l}\text { - Pelinggih } \\
\text { - Bale Gong } \\
\text { - Bale Pemiosan }\end{array}$ & $\begin{array}{l}234,62 \\
23,4 \\
56,58\end{array}$ & 314,6 & $35 \%$ & 595,3 & $65 \%$ & 909,9 \\
\hline \multirow[t]{3}{*}{$\begin{array}{l}\text { Madya } \\
\text { Mandala }\end{array}$} & $\begin{array}{l}\text { - Jaba } \\
\text { Tengah } \\
\text { Merajan }\end{array}$ & $\begin{array}{l}\text { - Bale Pesanekan } \\
\text { Merajan }\end{array}$ & 46,5 & 46,5 & $10 \%$ & 422,2 & $90 \%$ & 468,7 \\
\hline & - Natah & $\begin{array}{l}\text { - Saren Dangin } \\
\text { - Saren Daja } \\
\text { - Saren Delod } \\
\text { - Saren Dauh } \\
\text { - Bale Kantor } \\
\text { (3 unit) } \\
\text { - Bale Aling-aling } \\
\text { - Pewaregan } \\
\text { - Jineng }\end{array}$ & $\begin{array}{l}42,9 \\
51,2 \\
46,2 \\
46,2 \\
360 \\
763,3 \\
558,4 \\
77,2 \\
157,1 \\
24\end{array}$ & 2009,4 & $73 \%$ & 733 & $27 \%$ & 2742,4 \\
\hline & $\begin{array}{l}\text { - Jaba } \\
\text { Tengah } \\
\text { Puri }\end{array}$ & $\begin{array}{ll}\text { - } & \text { Bale Room } \\
\text { - } & \text { Bale Panjang } \\
\text { - } & \text { Bale Pesanekan } \\
& \text { Puri } \\
\text { - } & \text { Bale Bengong }\end{array}$ & $\begin{array}{l}288,8 \\
569,4 \\
85,8 \\
33,6\end{array}$ & 549,6 & $16 \%$ & 2876,2 & $84 \%$ & 3425,8 \\
\hline \multirow[t]{2}{*}{$\begin{array}{l}\text { Nista } \\
\text { Mandala }\end{array}$} & $\begin{array}{l}\text { - Jaba Sisi } \\
\text { Merajan }\end{array}$ & $\begin{array}{l}\text { - Bale Kulkul Merajan } \\
\text { - Garasi }\end{array}$ & $\begin{array}{l}55,7 \\
27\end{array}$ & 82,7 & $31 \%$ & 184,1 & $69 \%$ & 266,8 \\
\hline & $\begin{array}{l}\text { - Jaba Sisi } \\
\text { Puri }\end{array}$ & $\begin{array}{l}\text { - Bale Kulkul Puri } \\
\text { - Garasi }\end{array}$ & $\begin{array}{l}67,4 \\
230,2\end{array}$ & 297,6 & $22 \%$ & 1066,8 & $78 \%$ & 1364,4 \\
\hline
\end{tabular}


Pola ruang Puri Pemecutan pada tahun 1942 dan tahun 2016 dapat dilihat pada Gambar 1 dan Gambar 2.

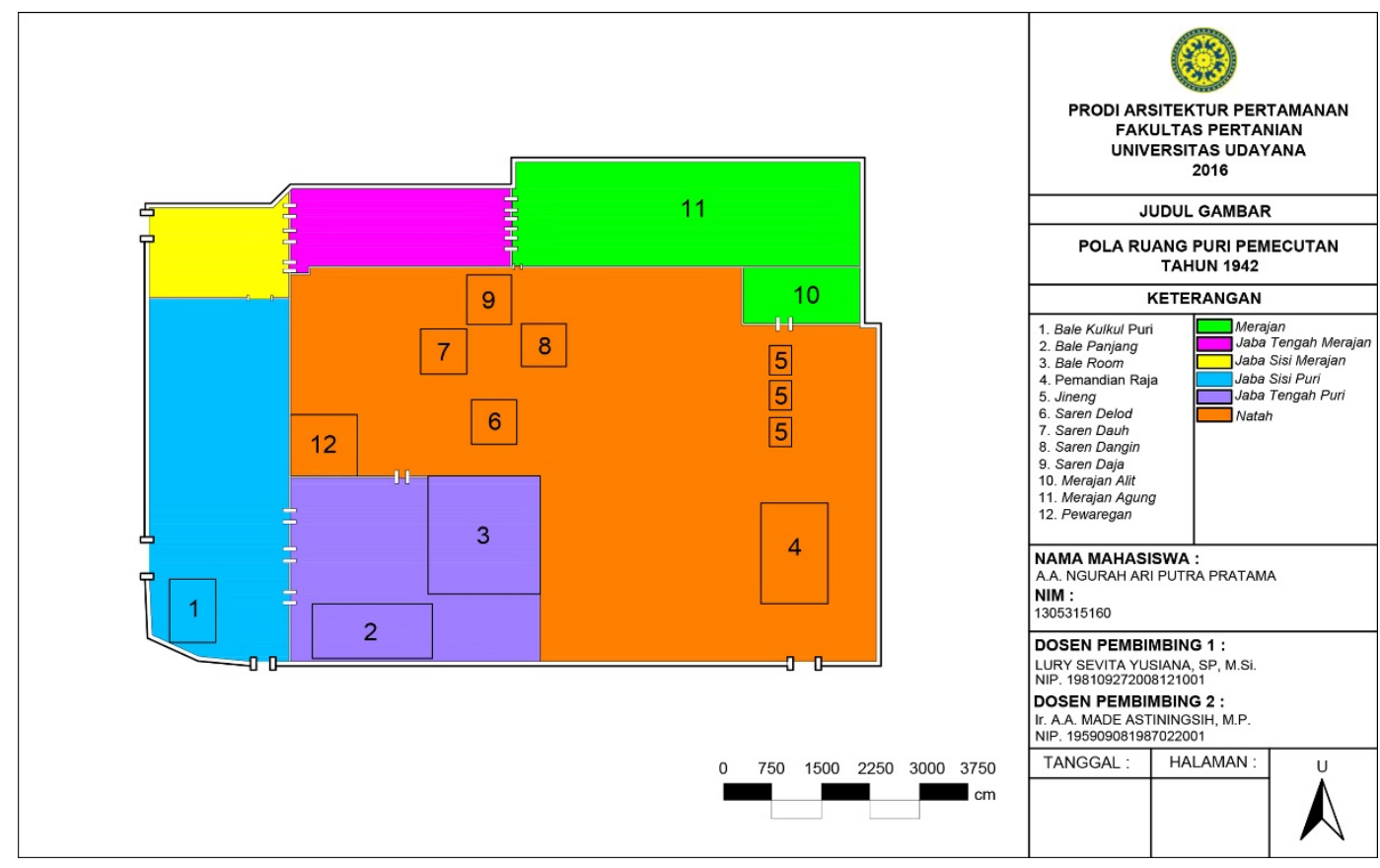

Gambar 1. Pola Ruang Puri Pemecutan Tahun 1942

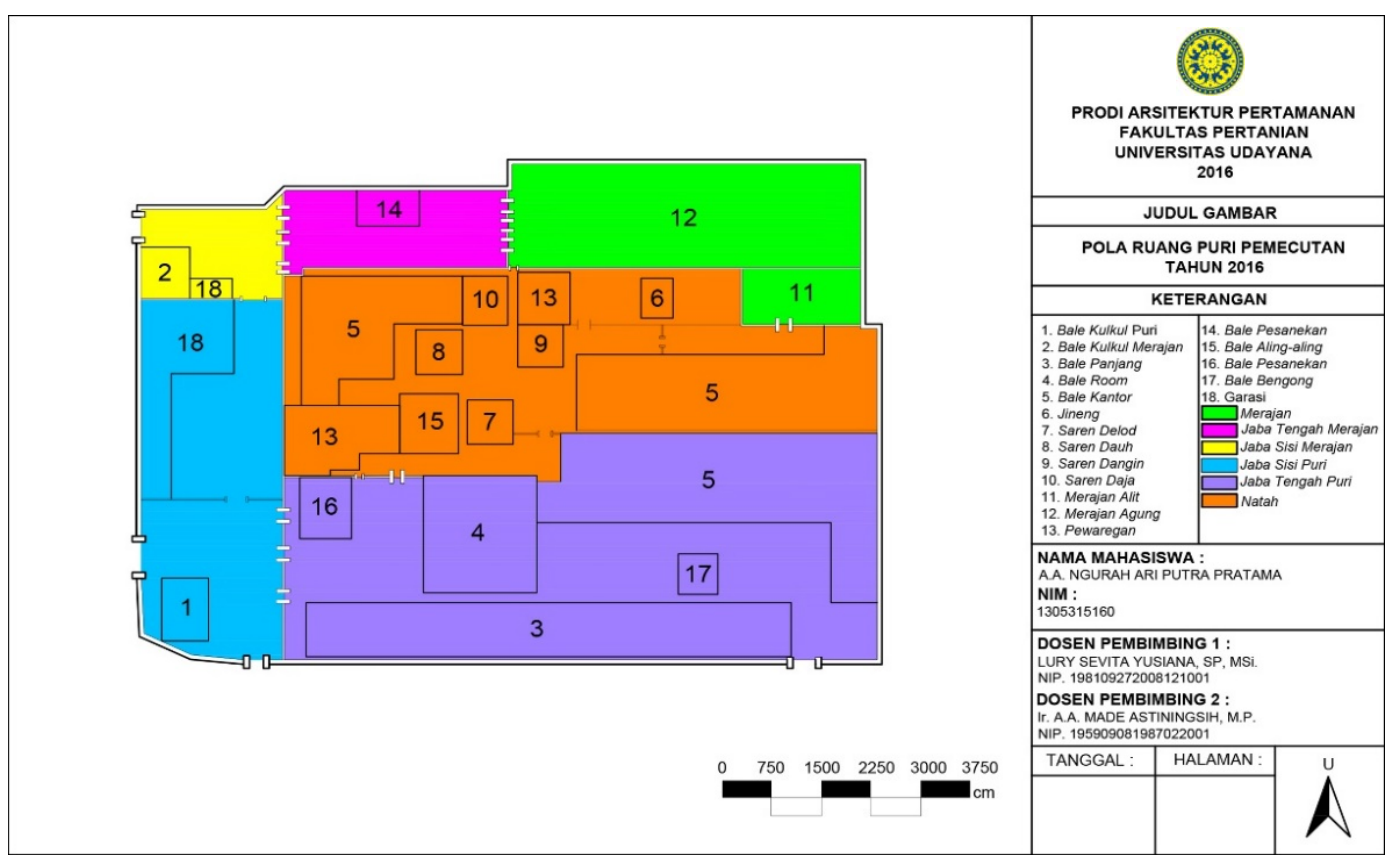

Gambar 2. Pola Ruang Puri Pemecutan Tahun 2016

\subsection{Identifikasi Fungsi Ruang Puri Pemecutan}

Pola ruang yang terdapat di Puri Pemecutan pada tahun 1942 dan tahun 2016 tidak mengalami perubahan jika dilihat segi fungsi dari masing-masing ruang yang ada, namun terjadi perubahan luas pada beberapa ruang di tahun 2016 yaitu ruang jaba tengah menjadi semakin luas dan ruang natah menjadi sempit. Ruang yang ada di Puri Pemecutan pada umumnya dibagi menjadi beberapa ruang, yaitu ruang Utama Merajan memiliki fungsi sebagai tempat melakukan persembahyangan oleh keluarga besar Puri Pemecutan, 
ruang Jaba Tengah Merajan merupakan ruang tengah dari Merajan Agung Puri Pemecutan yang berfungsi sebagai tempat berkumpul sebelum memasuki ruang Utama Merajan, ruang Jaba Sisi Merajan merupakan ruang terluar atau ruang Nista dari Merajan Agung Puri Pemecutan, ruang Natah atau ruang pribadi merupakan ruang yang difungsikan sebagai tempat melakukan kegiatan upacara keagamaan dan sebagai ruang berkumpul keluarga puri, ruang Jaba Tengah puri/ruang publik memiliki fungsi sebagai halaman tengah puri dan terletak sebelum memasuki ruang natah puri, dan ruang Jaba Sisi puri merupakan ruang terluar atau ruang Nista dari Puri Pemecutan.

\subsection{Analisis Perubahan Pola Ruang dan Fungsi Bangunan di Puri Pemecutan}

Perbedaan pola ruang puri tahun 1942 dengan tahun 2016 yaitu terlihat pada jumlah bangunan di masing-masing ruang. Saat ini terdapat bangunan di Puri Pemecutan yang letaknya tidak sesuai dengan fungsi ruang. Bangunan yang letaknya tidak sesuai yaitu bangunan Bale Kantor yang terletak di ruang Jaba Tengah atau ruang publik. Tidak sesuainya letak bangunan Bale Kantor karena fungsi Bale Kantor sebagai tempat tinggal keluarga puri sehingga letaknya harus di ruang Natah atau ruang pribadi dan tidak di ruang publik. Bangunan yang mengalami penambahan dan perubahan fungsi antara lain:

1. Saren Daja

Saren Daja pada tahun 1942 merupakan tempat tinggal bagi para puteri yang ada di Puri Pemecutan. Saren Daja saat ini berubah fungsi menjadi tempat berkumpulnya para penglingsir saat adanya upacara keagamaan di Puri Pemecutan, namun jika tidak ada upacara agama Saren Daja tidak memiliki fungsi. Berdasarkan aspek sosial perubahan ini terjadi karena saat ini keluarga puri sudah memiliki tempat tinggal sehingga Saren Daja saat ini tidak lagi berfungsi sebagai tempat tidur puteri keluarga puri.

2. Perubahan Fungsi Saren Dauh

Saren Dauh pada tahun 1942 memiliki fungsi sebagai tempat tidur bagi para putera yang ada di Puri Pemecutan. Saat ini Saren Dauh berubah fungsi menjadi tempat berlangsungnya kegiatan upacara keagamaan manusa yadnya. Berdasarkan dari aspek sosial, perubahan ini terjadi karena tingginya kebutuhan tempat upacara keagamaan keluarga puri dan dilihat dari aspek fisik, Saren Dauh tidak lagi berfungsi sebagai tempat tidur putera keluarga puri karena bentuk dari Saren Dauh yang terbuka sehingga tidak dapat lagi digunakan sebagai tempat tidur.

\section{Perubahan Fungsi Bale Room}

Bale Room di Puri Pemecutan pada tahun 1942 merupakan tempat tinggal raja dan istri Puri Pemecutan. Saat ini, Bale Room memiliki fungsi sebagai tempat penyimpanan pretima dan tempat untuk melakukan pertemuan atau paruman keluarga Puri Pemecutan. Perubahan fungsi yang terjadi di Bale Room ini terjadi karena Raja Puri Pemecutan saat ini lebih memilih tinggal di Bale Kantor. Perubahan fungsi Bale Room sebagai tempat melakukan pertemuan keluarga sangat baik, karena dari aspek sosial Bale Room sangat tepat digunakan sebagai tempat melakukan pertemuan atau paruman keluarga, sedangkan fungsi Bale Room sebagai tempat meletakkan pratima tidak tepat, karena pratima merupakan benda yang sangat disucikan oleh umat Hindu sehingga letaknya pun harus di tempat yang suci.

4. Bale Kantor

Bale Kantor di Puri Pemecutan merupakan penyebutan untuk tempat tinggal keluarga Puri Pemecutan. Bale Kantor dahulunya pada tahun 1942 tidak ada. Bale Kantor dibangun untuk memenuhi kebutuhan tempat tinggal keluarga puri. Berdasarkan aspek sosial Bale Kantor ini dibangun karena semakin banyaknya jumlah anggota keluarga puri sehingga kebutuhan akan tempat tinggal pun semakin tinggi, sedangkan dari aspek fisik Bale Kantor dibangun dengan bentuk rumah tinggal yang masih menggunakan gaya tradisional Bali.

\section{Bale Pesanekan}

Bale Pesanekan merupakan bale yang befungsi sebagai tempat untuk melakukan kegiatan pesantian atau kidung saat adanya kegiatan upacara di Puri Pemecutan, Bale Pesanekan ini dahulunya pada tahun 1942 tidak ada. Bale Pesanekan dibangun karena kurangnya tempat untuk melakukan kegiatan kidung/pesantian saat adanya upacara keagamaan di Puri Pemecutan, namun fungsi ini hanya berlaku hanya saat adanya upacara keagamaan, jika tidak ada upacara keagamaan Bale Pesanekan ini tidak memiliki fungsi.

\section{Bale Panjang}

Bale panjang yang terdapat di Puri Pemecutan memiliki fungsi sebagai tempat penerimaan tamu yang berkunjung di Puri Pemecutan dan juga beberapa ruang di bale panjang dijadikan sebagai gudang dan juga tidak terpakai. Berdasarkan dari aspek sosial, ruang yang tidak terpakai di bale panjang tersebut seharusnya dapat dimanfaatkan untuk kegiatan sosial atau digunakan untuk tempat tidur keluarga puri.

\section{Bale Aling-aling}

Bale Aling-aling di Puri Pemecutan pada tahun 1942 belum di bangun. Bale Aling-aling memiliki fungsi sebagai tempat untuk menghalangi pandangan sebelum masuk ke ruang Natah dan sebagai tempat berukumpulnya para undangan yang hadir saat adanya kegiatan upacara keagamaan di Puri Pemecutan namun, fungsi ini hanya digunakan saat adanya kegiatan upacara, jika tidak ada kegiatan upacara ruang yang 
terdapat di Bale Aling-aling hanya sebagai ruang kosong. Ruang yang terdapat di Bale Aling-aling seharusnya dapat dimanfaatkan sebagai tempat tidur ataupun fungsi lainnya agar ruang-ruang tersebut menjadi ruang yang berfungsi.

\section{Bale Bengong}

Bale Bengong merupakan bangunan yang dibangun setelah tahun 1942. Bangunan Bale Bengong yang ada di Puri Pemecutan saat ini hanya berfungsi sebagai tempat beristirahat, sehingga keberadaanya pun tidak terlalu penting untuk keluarga puri.

\section{Garasi}

Garasi yang terdapat di Puri Pemecutan berfungsi sebagai tempat untuk meletakkan kendaraan mobil maupun motor yang dimiliki oleh keluarga Puri Pemecutan. Garasi di Puri Pemecutan dibangun untuk memenuhi kebutuhan keluarga puri akan tempat meletakan kendaraan seperti mobil dan sepeda motor. Selain sebagai tempat kendaraan, saat adanya kegiatan upacara keagamaan seperti memukur, garasi di Puri Pemecutan juga dapat difungsikan sebagai tempat meletakkan gambelan.

\section{Bale Kulkul Merajan}

Bale Kulkul Merajan merupakan bangunan yang baru dibuat pada tahun 90'an. Bale Kulkul Merajan pada tahun 1942 belum dibangun oleh keluarga puri. Bale Kulkul Merajan memiliki fungsi sebagai tempat meletakkan Kulkul. Kulkul Merajan digunakan untuk memberikan pertanda jika di Merajan Puri Pemecutan sedang dilaksanakannya kegiatan upacara keagamaan dewa yadnya seperti upacara piodalan.

11. Bale Pesanekan Merajan

Bale Pesanekan Merajan merupakan bale yang befungsi Sebagai tempat berkumpul dan tempat untuk melakukan persiapan sebelum masuk ke ruang Merajan Agung. Bale Pesanekan Merajan ini dahulunya pada tahun 1942 belum dibangun Bale Pesanekan dibangun karena tidak adanya tempat yang dapat digunakan untuk melakukan persiapan sebelum masuk ke ruang Merajan Agung.

\subsection{Analisis Dampak Perubahan Masing-masing Ruang Terhadap Aktivitas Puri Pemecutan}

Bangunan yang terdapat di Puri Pemecutan pada tahun 1942 dan tahun 2016 memiliki beberapa perubahan fungsi bangunan serta adanya beberapa penambahan bangunan. Perubahan fungsi bangunan yang terjadi di Puri Pemecutan memiliki dampak jika dilihat dari beberapa aspek. Berdasarkan dari aspek sosial, adanya bangunan yang kurang difungsikan dengan baik oleh keluarga menyebabkan bangunan tersebut hanya menjadi ruang kosong. Banyaknya keluarga puri yang tinggal di luar puri, seharusnya bangunan-bangunan yang tidak difungsikan dapat digunakan sebagai tempat tinggal bagi keluarga puri yang tinggal di luar puri, jika semua keluarga Puri Pemecutan tinggal diluar puri akan berdampak pada sepinya Puri Pemecutan dan kurang adanya interaksi sosial yang terjadi antar sesama keluarga puri.

Dilihat dari aspek ekonomi, adanya bangunan di Puri Pemecutan saat ini yang hanya difungsikan sebagai bangunan kosong menjadikan bangunan tersebut tidak memiliki manfaat untuk keluarga puri, jika bangunan tersebut dimanfaatkan dengan baik dapat menghasilkan keuntungan untuk puri. Agar bangunan yang ada di puri dapat memberikan keuntungan dari segi ekonomi, keluarga puri dapat menjadikan salah satu bangunan sebagai museum. Adanya museum di Puri Pemecutan dapat mendatangkan keuntungan untuk keluarga puri karena dengan adanya museum ini menjadikan Puri Pemecutan sebagai tempat wisata sejarah yang ada di Kota Denpasar.

\subsection{Rekomendasi Tata Ruang}

Berdasarkan hasil analisis dan sintesis yang telah dilakukan mengenai tata ruang Puri Pemecutan, rekomendasi tata ruang yang dapat dilihat pada Gambar 3. Pola Ruang Puri Pemecutan pada tahun 1942 dengan pola ruang tahun 2016 memiliki perbedaan dilihat dari segi jumlah bangunan dan perubahan fungsi bangunan. Tahun 2016 terdapat banyak penambahan bangunan di Puri Pemecutan, penambahan bangunan ini terjadi karena banyaknya kebutuhan ruang bagi keluarga puri, namun saat ini banyak bangunan yang ada di Puri Pemecutan tidak dimanfaatkan dengan baik sehingga hanya menjadi gudang dan bangunan kosong. Bangunan-bangunan puri yang dapat dimanfaatkan yaitu Bale Aling-aling, Saren Daja, dan Bale Panjang. Bale Aling-aling dan Saren Daja saat ini hanya difungsikan jika sedang ada upacara keagamaan di puri, oleh karena itu bale tersebut dapat digunakan sebagai tempat tidur untuk keluarga puri, sehingga menjadikan puri lebih ramai dan mengurangi keluarga yang tinggal diluar puri, sedangkan Bale Pesanekan yang saat ini berfungsi sebagai tempat untuk melakukan kegiatan pesantian atau kidung saat adanya kegiatan upacara dapat juga difungsikan sebagai tempat penerimaan tamu, karena Bale Pesanekan terletak di ruang publik sehingga fungsinya pun harus sesuai dengan letaknya. 


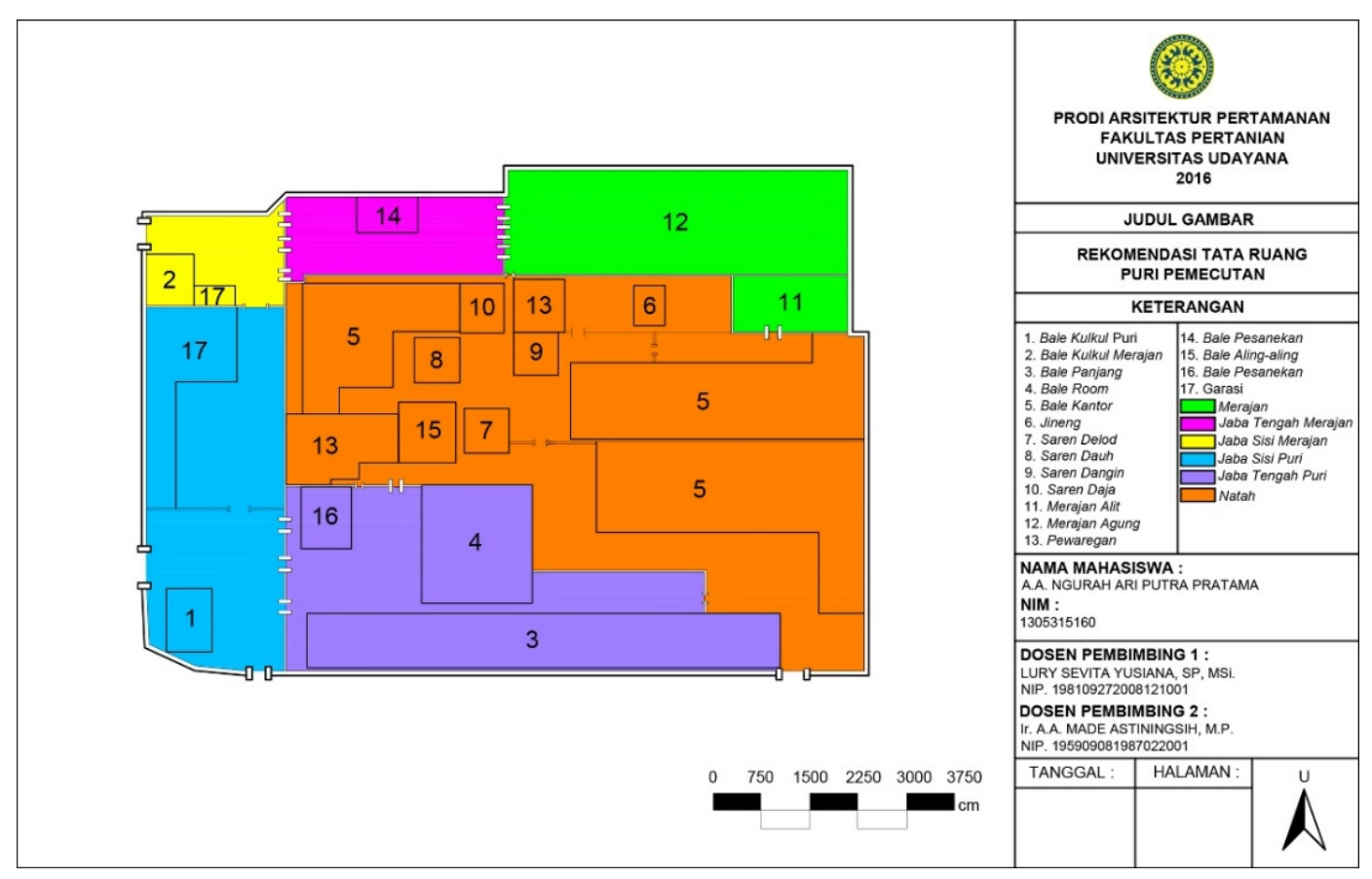

Gambar 3. Rekomendasi Tata Ruang Puri Pemecutan

Ruang Jaba Tengah puri terdapat bangunan Bale Kantor yang berfungsi sebagai tempat tinggal keluarga puri. Bangunan Bale Kantor pada umumnya termasuk dalam ruang pribadi sehingga letaknya pun harus dipindahkan ke ruang Natah atau ruang pribadi agar sesuai dengan letak dan fungsinya, agar Bale Kantor di Puri Pemecutan letaknya tidak lagi di ruang publik dapat dibuatkan pembatas sehingga Bale Kantor tersebut tidak termasuk pada ruang publik. Bangunan Bale Bengong yang terdapat di ruang Jaba Tengah dapat dihilangkankan, karena fungsinya tidak terlalu dibutuhkan oleh keluarga puri.

Bangunan di Puri Pemecutan yang fungsinya tidak sesuai dengan letaknya yaitu Bale Room. Bale Room yang terdapat di Puri Pemecutan saat ini berfungsi sebagai tempat melakukan pertemuan keluarga dan sebagai tempat meletakkan pratima. Berdasarkan letak Bale Room yang berada di ruang publik sangat tidak sesuai dengan fungsi Bale Room sebagai tempat meletakkan pratima. Pratima merupakan benda yang disucikan, oleh karena itu pratima sangat tepat apabila diletakkan di ruang Utama Merajan.

Bale Panjang yang ada di Puri Pemecutan saat ini berfungsi sebagai tempat penerimaan tamu dan sebagai gudang. Gudang yang ada di Bale Panjang dapat digunakan sebagai museum Puri Pemecutan. Berdasarkan analisis dan wawancara yang dilakukan pembuatan museum memiliki dampak yang sangat positif untuk keluarga puri. Dampak positif dari adanya museum yaitu puri memperoleh keuntungan ekonomi, dapat menjadi tempat pembelajaran mengenai sejarah Puri Pemecutan, dan dapat menjadi salah satu alat pemersatu keluarga puri seperti yang diharapkan oleh pelingsir Puri Pemecutan.

\section{Simpulan dan Saran \\ 4.1 Simpulan}

Berdasarkan hasil penelitian tentang Identifikasi Pola Ruang dan Perubahan Fungsi Ruang Puri Pemecutan dapat disimpulkan bahwa Pola Ruang Puri Pemecutan secara umum dibagi menjadi beberapa ruang yaitu Ruang Utama Merajan, Ruang Jaba Tengah Merajan, Ruang Jaba Sisi Merajan, Ruang Natah, Ruang Jaba Tengah Puri, dan Ruang Jaba Sisi Puri. Perbedaan dari pola ruang puri tahun 1942 dengan tahun 2016 terletak pada bertambahnya jumlah bangunan dan perubahan fungsi bangunan pada masing-masing ruang yang ada. Bangunan di Puri Pemecutan pada tahun 1942 yang mengalami perubahan fungsi yaitu Saren Daja, Saren Dauh, Bale Room, dan Pemandian Raja. Perubahan fungsi bangunan yang terjadi di Puri Pemecutan memiliki dampak jika dilihat dari beberapa aspek yaitu aspek sosial dan aspek ekonomi.

\subsection{Saran}

Saran yang dapat diberikan untuk penelitian ini yaitu perlu dilakukannya penelitian lebih lanjut mengenai penataan Natah di Puri Pemecutan dan perlu dilakukan penelitian mengenai fungsi puri dimasa mendatang, karena semakin berkembangnya zaman dapat mempengaruhi fungsi puri kedepannya. 


\section{Daftar Pustaka}

Badan Meteorologi Klimatologi dan Geofisika. 2015. Pelayanan Jasa Informasi Klimatologi. Stasiun Meteorologi Klas I Ngurah Rai. Denpasar.

Gelebet, I.N. 1986. Arsitektur Tradisional Daerah Bali. Denpasar : Depdikbub.

Putra, I.G.M. 1990. Kekuasaan dan Transformasi Arsitektur, Suatu Kajian Budaya Terhadap Kasus Puri Agung Tabanan. Program Pasca Sarjana Universitas Udayana, Denpasar. Tidak diterbitkan.

Soekanto, S. 1990. Sosiologi: Suatu Pengantar. Jakarta : Rajawali Pers.

Supraptomardjo, M. 1970. Peta Tanah Tinjau Pulau Bali. Junus Dai.

Wiana, IK. 2006. Memahami Perbedaan Catur Warna, Kasta, dan Wangsa. Penerbit Paramita. Surabaya 